\title{
Living with breast cancer: Patients' journey within the Greek National Health System
}

\author{
Daphne Kaitelidou', Maria Kalogeropoulou², Theofanis Katostaras ${ }^{3}$, \\ Olympia Konstantakopoulou4*, Panagiotis Minogiannis ${ }^{5}$, Alexandra Skitsou ${ }^{6}$, \\ Olga Siskou', Georgios Charalampous ${ }^{8}$, Alexandros Ardavanis ${ }^{9}$, \\ Lykourgos Liaropoulos ${ }^{10}$ \\ ${ }^{1}$ Associate Professor, Faculty of Nursing, National and Kapodistrian University of Athens, \\ Center for Health Services Management and Evaluation
}

${ }^{2} P h D$, Faculty of Nursing, National and Kapodistrian University of Athens, Center for Health Services Management and Evaluation

${ }^{3}$ Associate Professor, Faculty of Nursing, National and Kapodistrian University of Athens

${ }^{4} \mathrm{PhDc}$, Faculty of Nursing, National and Kapodistrian University of Athens, Center for Health Services Management and Evaluation

${ }^{5} \mathrm{PhD}$, Former Director of Aghios Savvas Cancer Hospital

${ }^{6}$ PhD, Frederick University of Cyprus

'PhD, Faculty of Nursing, National and Kapodistrian University of Athens, Center for Health Services Management and Evaluation

${ }^{8}$ MD, HIPPOKRATEION General Hospital of Athens, Department of Health Management, National School of Public Health, Athens

${ }^{9} \mathrm{MD}$, Director of the A' Oncology Department, Aghios Savvas Cancer Hospital

10Professor Emeritus, Faculty of Nursing, National and Kapodistrian University of Athens, Center for Health Services Management and Evaluation

Received 16 October 2015; Accepted 15 December 2015

\begin{abstract}
Background: Process mapping (a patient-centred method) and recording the medical, nursing and administrative staff's views involved in the provision of care help us understand patients' experience regarding the constraints, delays and bottlenecks of healthcare service processes and identify areas of improvement.

Patients and Methods: Time information and data were collected through time and motion study with regard to the path patients with breast cancer follow in two public hospitals (sample of 86 patients) and a semi-structured questionnaire was administered to medical, nursing and administrative staff (sample of 14 employees).

Results: The amount of time required in total for the prescription process was increased up to seve7 times compared to the beneficial amount of time, and the longest delays in patients' waiting time were observed with regard to the process of chemotherapy (more than 2 hours and 40 minutes, in some cases). About $92.3 \%$ of the staff of the two hospitals prioritized the malfunctioning of theCcentrallinformationSsystem as the most important factor and more than $75 \%$ of the study participants mentioned that several administrative and technical aspects have a negative and significant effect on the time required to prescribe the necessary medicines for the treatment of patients.

Conclusions: The lack of understanding of the hospital's processes and spatial infrastructure by most patients, the lack of an electronic patient record system and central information system are highlighted as the main issues that contribute decisively to the increase in the non-beneficial time that patients with breast cances have to spend nowadays in hospitals of the NHS in Greece.
\end{abstract}

Keywords: Process mapping • Patients' journey • Breast cancer patients • Waiting times • Hospital staff's views

(C) De Gruyter Open 


\section{Introduction}

The process mapping in the provision of healthcare services is a useful diagnostic tool for the identification of problems that may come up, such as the constraints in the single steps for the completion of processes, delays, bottlenecks, the processes that are repeated or superfluous (1, and the identification of the different dimensions in the provision of health services that need improvement (2). Process mapping, which should set out the principles for the redesign of all services, the demand, the occupancy, the activities, the management of patient wait, the modelling of flow and the design of services, providing information and solutions for improvement (3-6), is a method focused on the patient, which helps us to understand the experience they have from the health system and the processes for the provision of health services.

Understanding the path of patients within the healthcare system and the steps they follow to complete the processes related to their healthcare is one of the most important features of assessing the quality of health services, as without a clear understanding of the individual processes in the provision of healthcare services, we would risk determining the steps followed by the patient in a way that not only would not improve patients' flo, but in fact would result in longer delays and more problems. The problems identified with the use of process mapping are related to wrong scheduling, poor management or even the lack of the necessary information technology (IT) systems, resulting in a negative impact to the healthcare system and leading to poor patients' flow, which in turn affects the quality of care, patient safety, the satisfaction of patients and staf, and the efficient use of resources (1). Poor patients' flow within the healthcare organization (during the provision of healthcare) is due to constraints and, generallyo bottleneck in various departments of the health unit. The term "bottleneck" refers to the case in which the flow of patients is "blocked", causing wait and delays in any part of the system. Bottleneck interrupts the natural flow and obstructs motion along the healthcare pathway (7). Another cause of delays during the provision of healthcare, which also creates inconvenience to patients and staff, is the existence of parallel processes (8). Examples of parallel processes could b: the process from the moment a blood sample is transferred to the laboratory until the time the physician receives the results, or the process involving the retrieval of the patient's medical record up to its return to the archives (7).
Studies that have been carried out in health units across Europe (mainly in the United KingdoK), Australia and the United Statea (9-12, showed that the use of process mapping (by recording constraints, delays and bottlenecks, and also identifying those processes that required redesign) had multiple positive results in the reduction of waiting times for the examination by the attending physician and the conduction of laboratory tests, the improvement of patients' flow time, the reduction of queues, the reduction of the time needed from referral to the start of treatment in the early stages of cancer, the reduction of the average duration of hospitalisation and the reduction of the staff's "paths".

Also, a very important parameter for addressing dysfunctional steps in the healthcare services provision processes and identifying the areas that need improvemen, is to record the views of the medical and nursing staff concerned, as they are the main source of valuable information (along with patients) regarding the quality level of health services provided.

The aim of this study was to map the path of patients with breast cancer in the NHS through the time and motion study, from the moment patients enter the hospital until they leave, and to record the views of the medical and nursing staff involved in the provision of health services.

\section{Patients and Methods}

The analysis was carried out b: (a) collecting time information and data with regard to the path patients with breast cancer follow in two public hospitals (Hospital A an, B) (convenience sample of 86 patients), through the time and motion study from the moment patients enter the hospital until they leave (the observation was made by a team of researchers after the informed consent of patients and without the knowledge of the directly concerned staff, to avoid deterioration of results), and (b) using a semi-structured questionnaire in order to record the views of the medical, nursing and administrative staff (convenience sample of 14 workers at the two hospitals) on the factors that may affect the prescription and provision time of required medicine, and the factors that are constraints to the smooth motion of patients in healthcare services (the questionnaires were addressed to the Medical,Nnursing andAadministrative staff of thePpublicHhospitals where the study was carried ou, and were filled in anonymously). 
Table 1. Total and beneficial times by process and hospital.

\begin{tabular}{c|ccc}
\hline & Hospital & Average total time & $\begin{array}{c}\text { Average beneficial time } \\
\text { (time during which the processes carried out relate } \\
\text { strictly to the provision of therapeutic care) }\end{array}$ \\
\hline \hline \multirow{2}{*}{ Per os prescription } & Hospital A & $1 \mathrm{~h}$ & $20 \mathrm{~min}(33.7 \%)$ \\
& Hospital B & $1 \mathrm{~h} 41 \mathrm{~min}$ & $12 \mathrm{~min}(11.8 \%)$ \\
Chemotherapy & Hospital A & $4 \mathrm{~h} 57 \mathrm{~min}$ & $125 \mathrm{~min}(43.8 \%)$ \\
\hline
\end{tabular}

\section{Results}

\section{Time and motion study results}

According to the results (Table 1), the amount of time required in total for the prescription process was increased up to seve7 times compared to the beneficial amount of time, which in some cases did not exceed $12 \%$ of the total amount of time. As to the waiting time of patients, the longest delays concern the process of chemotherapy, with patients waiting more than 2 hours and 40 minutes in some cases. Certainly, it is true that in terms of chemotherapy, beneficial time is not easy to assess accurately because during wait, the dissolution of cytostatic medicines takes place, the duration of which is not known to researchers. However, according to responses received by researchers from a sample check, the time in most cases of dissolution does not exceed five to seve7 minutes, except for two chemotherapy preparations for which the time required is longer (estimated at around half an hour). Given this limitation, the total average time required for the chemotherapy of patients with breast cancer at Hospital A was 4 hours and 57 minutes, whilse, out of it, only 2 hours and 5 minutes is estimated to be beneficial (43.8\%). Respectively, the total average time required for the chemotherapy of patients with breast cancer at Hospital B was 3 hours and 35 minutes, whilse, out of it, only 1 hour and 38 minutes is estimated to be beneficial (47.8\%).

\section{The views of the medical, nursing and administrative staff}

Concerning the factors that affect the time required to prescribe the necessary medicines for the treatment of patients (from the moment patients enter the hospital until they leave), $92.3 \%$ of the staff of the two hospitals prioritised the malfunctioning of the central information system as the most important factor, with the factors of
Table 2. Factors that affect the time required to prescribe the necessary medicines for the treatment of patients (in descending order of importance).

\begin{tabular}{|c|c|}
\hline $\begin{array}{l}\text { Factors that affect the time required to } \\
\text { prescribe the necessary medicines for the } \\
\text { treatment of patients }\end{array}$ & YES \\
\hline $\begin{array}{c}\text { Malfunctioning of the central information system for } \\
\text { prescription }\end{array}$ & $92.3 \%$ \\
\hline Lack of medical personnel & $83.3 \%$ \\
\hline Lack of electronic patient record & $80.0 \%$ \\
\hline $\begin{array}{l}\text { Lack of a single information system between the bodies } \\
\text { concerned }\end{array}$ & $77.8 \%$ \\
\hline Lack of coordination between the bodies concerned & $66.7 \%$ \\
\hline Lack of administrative staff & $62.5 \%$ \\
\hline Lack of equipment & $55.6 \%$ \\
\hline Inability to prescribe in the afternoon hours & $33.3 \%$ \\
\hline $\begin{array}{l}\text { Lack of familiarity of physicians with the use of modern } \\
\text { technology }\end{array}$ & $33.3 \%$ \\
\hline Failure to observe working hours by the relevant staff & $25.0 \%$ \\
\hline Lack of nursing personnel & $12.5 \%$ \\
\hline
\end{tabular}

lack of medical staff, electronic patient record, a single information system between the bodies concerned, coordination of the bodied concerned, administrative staff and equipment following (the percentages of positive responses being $83.3 \%, 80 \%, 77.8 \%$, $66.7 \%, 62.5 \%$ and $55.6 \%$, amongst all respondents, respectively, for each factor).

On the contrary, one of three respondents (33.3\%) considered the inability to prescribe in the afternoon hours and the lack of familiarity of physicians with the use of modern technology as an important factor, and $25 \%$ stated the failure to observe working hours by the relevant staff. Only $12.5 \%$ of respondents considered the lack of nursing staff as an important factor (Table 2).

Especially as far as the malfunctioning of the central information system for prescription is concerned, $91.7 \%$ of respondents who consider it an important factor replied that the e-Prescription system hangs 'from moderately to very much', that many steps are 
Table 3. Malfunctioning of the central information system for prescription.

\begin{tabular}{|c|c|c|}
\hline & & $\begin{array}{c}\text { Malfunctioning of the central information system } \\
\text { for prescription } \\
\text { YES }\end{array}$ \\
\hline \multirow{4}{*}{ The e-Prescription system 'hangs' } & Slightly & $8.30 \%$ \\
\hline & Moderately & $33.30 \%$ \\
\hline & Much & $41.70 \%$ \\
\hline & Very much & $16.70 \%$ \\
\hline \multirow{3}{*}{$\begin{array}{l}\text { Many steps are required for the filling in } \\
\text { of the prescription }\end{array}$} & Slightly & $8.30 \%$ \\
\hline & Moderately & $41.70 \%$ \\
\hline & Much & $25.00 \%$ \\
\hline \multirow{5}{*}{$\begin{array}{l}\text { The e-Prescription software is not user } \\
\text { friendly }\end{array}$} & Very much & $25.00 \%$ \\
\hline & Slightly & $8.30 \%$ \\
\hline & Moderately & $58.40 \%$ \\
\hline & Much & $25.00 \%$ \\
\hline & Very much & $8.30 \%$ \\
\hline
\end{tabular}

required for the filling in of the prescription and that the e-Prescription software is 'not user friendly' (Table 3 ).

Table 4 lists the views of the medical, nursing and administrative staff regarding the extent to which certain factors (whether the e-Prescription system 'hangs', the existence of many steps for the filling in of the prescription, whether the e-Prescription software is 'user friendly', the existence of State prescribing restrictions, whether a special committee of the hospital needs to approve the administration of medicines, whether approval is required by another competent committee, the existence of long queues for prescription at the hospital, the existence of problems in the sequence of administrative acts, the existence of problems in the organising of appointment making and the existence of problems in e-Prescription process) affect the time required to prescribe the necessary medicines for the treatment of patients.

The vast majority of respondents replied that the existence of problems in the e-Prescription process (e.g. lack of time of physicians), the existence of problems in the organising of appoint making (e.g. appointments of many patients at the same time, resulting in the increase of waiting time), the existence of problems in the sequence of administrative acts (e.g. gaps between the steps to perform a single act), the existence of State prescribing restrictions (e.g. mandatory quarterly prescription) and the existence of long queues for prescription in hospitals affect from 'Moderately' to 'Very Much' the time required to prescribe the necessary medicines for the treatment of patients $(84.7 \%, 84.6 \%$, $83.3 \%, 77 \%$ and $75 \%$ of respondents, respectively). On the contrary, $69.3 \%$ and $53.9 \%$ of the study participants replied that the factors of the necessary approval of medicines administration by a special committee of the hospital and other competent committee (insurance committee of the Greek National Health Service Organisation, prefectural-regional committee, disability certification centres) affect from 'Not at all' to 'Slightly' the time required to prescribe the necessary medicines for the treatment of patients.

\section{Conlusions and Recommendations}

From the study results, it becomes evident that the main problems contributing decisively to the increase in the time spent in hospital and, overall, to the process of medicines receipt by patients with breast cancer are the lack of understanding of the hospital's processes and spatial infrastructure (i.e. waiting in the area of the counter, when they should go to the area where appointments are confirmed, so patients who come to the hospital for the first time follow the wrong path and get delayed), the service of patients who do not have a scheduled appointment as unexpected incidents and/or the involvement of the physician in other tasks during the process of prescribing (i.e. taking phone calls), the delay in finding the medical record because of the lack of an electronic patient record system, the inability or the delay in filling in the prescription because of the 'not user-friendly' e-Prescription software, and the long waiting time from the scheduled time of the appointment to the moment the patient enters the physician's office, because of the fact that physicians are also involved in other tasks, resulting in them getting to their office late. 
Table 4. Extend to which certain factors affect the time required to prescribe the necessary medicines for the treatment of patients.

\begin{tabular}{|c|c|c|c|c|c|}
\hline & $\begin{array}{l}\text { Not at } \\
\text { all }\end{array}$ & Slightly & Moderately & Much & $\begin{array}{l}\text { Very } \\
\text { much }\end{array}$ \\
\hline The e-Prescription system 'hangs' & & $15.30 \%$ & $38.50 \%$ & $23.10 \%$ & $23.10 \%$ \\
\hline Many steps are required for the filling in of the prescription & & $15.30 \%$ & $38.50 \%$ & $23.10 \%$ & $23.10 \%$ \\
\hline The e-Prescription software is not user friendly & & $15.40 \%$ & $53.80 \%$ & $23.10 \%$ & $7.70 \%$ \\
\hline Existence of State prescribing restrictions & $7.60 \%$ & $15.40 \%$ & $23.10 \%$ & $23.10 \%$ & $30.80 \%$ \\
\hline $\begin{array}{l}\text { The administration of medicines needs to be approved by a special } \\
\text { committee of the hospital }\end{array}$ & $46.20 \%$ & $23.10 \%$ & $7.70 \%$ & $7.70 \%$ & $15.30 \%$ \\
\hline $\begin{array}{l}\text { The approval by a committee is necessary (insurance committee of } \\
\text { the Greek National Health Service Organization, prefectural-regional } \\
\text { committee, disability certification centres) }\end{array}$ & $15.40 \%$ & $38.50 \%$ & $30.70 \%$ & $7.70 \%$ & $7.70 \%$ \\
\hline Existence of long queues for prescription in hospitals & & $25.00 \%$ & & $41.70 \%$ & $33.30 \%$ \\
\hline Existence of problems in the sequence of administrative acts & & $16.70 \%$ & $33.30 \%$ & $33.30 \%$ & $16.70 \%$ \\
\hline Existence of problems in the organising of appointment making & & $15.40 \%$ & $15.40 \%$ & $30.70 \%$ & $38.50 \%$ \\
\hline Existence of problems in the e-Prescription process & & & $15.30 \%$ & $38.50 \%$ & $46.20 \%$ \\
\hline
\end{tabular}

The relevant literature confirms the positive relationship between long waiting times and patient dissatisfaction with the quality of healthcare services provided (13-15). Specifically, the long waiting time for chemotherapy is one of the most common and significant problems that contribute to the increased dissatisfaction of patients (16). According to Anderson et al., the poor staffing of the hospital with medical staff and the service of a large volume of patients lead to reduced examination times and increased waiting times, resulting in low levels of patient satisfaction (17).

In this context, and in order to reduce waiting times and optimise the relation between beneficial time (time during which the processes carried out relate strictly to the provision of therapeutic care) and the total time patients spend in the hospital for the completion of prescription and chemotherapy-related processes, a number of improvement measures can be adopted. First, the room for improvement in scheduling appointments through better use of IT, secretarial/phone support and the Internet, is real and would contribute to reducing nonbeneficial time spent in the hospital. With respect to the preparation of materials/supplies, the standardisation of internal processes in order to quickly serve patients is possible and worth studying further. An exception is the dissolution of cytostatic medicines, which correctly requires the presence of the patient at the hospital, the examination by the physician and the appropriate treatment approval, as a possible loss in medicines would be a great financial loss for the hospital. Also, the deployment of the suitable administrative support staff to physicians would improve patients' flow times, as internal coordination with other departments of the hospital; this would enable greater speed and safer prescribing and would be more effective; the various documents requests would be processed faster, and visits to the physician would be potentially decreased if a remote monitoring of proper compliance with the physician's instructions would take place. The application of the electronic signatures recognition would also significantly reduce waiting times for the administration of the medicine, as the confirmation of the signature's authenticity would not be needed and prescription processes would speed up. Finally, the limitation of extraordinary/unexpected appointments would reduce the waiting time of the regular ones if scheduled appointments were kept strictly and the extraordinary ones were minimised (of course, the hospital's redesign must take into account the fact that the increase in uninsured persons and the general reduction of available income leads many people to morning appointments, even for simple prescription).

The aim of each administration is to make optimal use of the key factors in the quality of services offered (clinical effectiveness, efficiency in resource use and patient satisfaction), which would allow a series of corrective actions such as reducing the inconvenience of patients, by reducing non-beneficial time, so as to achieve the above objectives. The relevant literature shows that when measures are taken (as the foregoing) for the increase in patient satisfaction, the responsiveness of 
the system to the growing needs of users has increased simultaneously. Of course, we should also take into account the systemic environment within which hospital administrations work, especially during the economic crisis, which is mainly characterised by the lack of measurement and benchmarking of hospitals in the three aforementioned dimensions of quality.

However, this remains very far from the institutionalised operation of hospitals and the concrete objectives as to their operation. Hospitals are not assessed based on these three criteria but are compared primarily on the basis of certain financial indicators of budget performance and expenditures. As, therefore, the hospital's sustainability does not depend today neither on its clinical effectiveness nor on patient satisfaction, the necessary framework of incentives is not created, let alone improve incidents such as the unnecessary stay of patients because of the lack of internal coordination.

In this context, it is obvious that a new assessment framework should be created, one that will make the criterion of patient satisfaction and better internal coordination a decisive factor for the assessment of quality as far as services offered are concerned.

\section{References}

[1] Trebble, T., Hansi, N., Hydes, T., Smith, M.A., Baker, M. (2010). Process mapping the patient journey: an introduction. BMJ, 2010, 341.

[2] Kim CS, Spahlinger DA, Kin JM, Billi JE. Lean health care: What can hospitals learn from a worldclass automaker?. Journal of Hospital Medicine, 2006, 1.3: 191-199.

[3] Goodrich, J., Cornwell, J. Seeing the Person in the Patient; the Point of Care Review Paper. London: The King's Fund. 2008.

[4] Richards, Nick; Coulter, Angela. Is the NHS Becoming More Patient-centred?: Trends from the National Surveys of NHS Patients in England 200207. Picker Institute Europe, 2007.

[5] Scott, Linda; Caress, Ann-Louise. Shared governance and shared leadership: meeting the challenges of implementation. Journal of Nursing Management, 2005, 13.1: 4-12.

[6] Wales, Ann. Managing knowledge to support the patient journey in NHS Scotland: strategic vision and practical reality. Health Information \& Libraries Journal, 2005, 22.2: 83-95.

[7] Graban M. Overview of lean for hospital. Lean hospitals. New York: Taylor \& Francis, 2009.

[8] NHS Modernisation Agency (2005). Process mapping, analysis and redesign. London: Department of Health, pp 1-40.

[9] Kelly M.J., Lloyd T.D.R., Marshall D., Garcea G.,. Sutton C. D, Beach M. A snapshot of MDT working and patient mapping in the UK colorectal cancer centres in 2002. Colorectal Disease, 2003, 5.6: $577-581$
[10] NHS Institute for Innovation and Improvement. Process mapping, analysis and redesign. London: Department of Health, 2007, pp 1-43.

[11] NHS Scotland Event. Reducing the length of stay for patients with Fractured hip. NHS Scotland, Edinburgh, 2008.

[12] Dickson, Eric W., et al. Use of lean in the emergency department: a case series of 4 hospitals. Annals of emergency medicine, 2009, 54.4: 504-510.

[13] Zoller, James S.; Lackland, Daniel T.; Silverstein, Marc D. Predicting patient intent to return from satisfaction scores. The Journal of ambulatory care management, 2001, 24.1: 44-50.

[14] Dansky, Kathryn H.; Miles, Jeffrey. Patient satisfaction with ambulatory healthcare services: waiting time and filling time. Journal of Healthcare Management, 1997, 42.2: 165.

[15] Huang, Xiao-Ming. Patient attitude towards waiting in an outpatient clinic and its applications. Health Services Management Research, 1994, 7.1: 2-8.

[16] Coates, Alan, et al. On the receiving endpatient perception of the side-effects of cancer chemotherapy. European Journal of Cancer and Clinical Oncology, 1983, 19.2: 203-208.

[17] Anderson, Roger T.; Camacho, Fabian T.; Balkrishnan, Rajesh. Willing to wait?: the influence of patient wait time on satisfaction with primary care. BMC Health Services Research. 2007; 7.1: 31. 